\title{
Genetic variability in goitred gazelle Gazella subgutturosa subgutturosa: allozymes and karyotypes
}

\author{
Arnd SCHREIBER and Gisela von HEGEL
}

\begin{abstract}
Schreiber A. and von Hegel G. 1999. Genetic variability in goitred gazelle Gazella subgutturosa subgutturosa: allozymes and karyotypes. Acta Theriologica 44: 55-66.

The electrophoretic polymorphism of blood proteins, and karyotypes, were studied in up to 33 captive-bred Persian goitred gazelles Gazella s. subgutturosa (Güldenstaedt, 1780 ). Allozymes, haemoglobins and serum proteins representing 33 putative genetic loci displayed four biallelic polymorphisms (carbonic anhydrase, malate dehydrogenase, mannose phosphate isomerase, transferrin), resulting in a percentage polymorphism of $p=0.121$, and an expected heterozygosity of $H_{e}=0.047$. Six males had $2 \mathrm{n}=31$, and seven females $2 \mathrm{n}=30$ chromosomes. This sex-specific difference was due to an $\mathrm{X}$-autosomal translocation, coupled with a $\mathrm{XY}_{1} \mathrm{Y}_{2}$ sex determining system in males. Neither karyotypes nor protein polymorphism provided evidence to explain the high mortality of newborn goitred gazelles.

Zoologisches Institut I der Universität, Im Neuenheimer Feld 230, D-69120 Heidelberg, Germany (AS), e-mail: r05@ix.urz.uni-heidelberg.de; Zoologischer Garten Karlsruhe, Ettlinger Strasse 6, D-76137 Karlsruhe, Germany (GH)

Key words: Gazella subgutturosa, biochemical genetics, sex chromosomes, captive breeding, Bovidae
\end{abstract}

\section{Introduction}

The gazelles of the subfamily Antilopinae (Bovidae) have received more attention from population geneticists than have most other non-domesticated bovids (Templeton et al. 1987, Georgiadis et al. 1990, Granjon et al. 1991, Bigalke et al. 1993, Vassart 1994, Vassart et al. 1994, 1995a, Schreiber et al. 1997). Two reasons may explain this preferential treatment of antelopines by students of biochemical-genetic variability: (1) morphological characters produced conflicting taxonomic classifications of Gazella spp., and (2) the breeders of several rare gazelle species in zoos or game parks frequently experienced unsatisfactorily low breeding performance which could have a genetic cause.

The traditional characters of gazelle systematics are provided by horn form, skull shape and pelage pigmentation. On this basis, different authors grouped the approximately 50 described Gazella taxa into 12 to 16 species (Groves 1969, 1983, 1985, 1988, Lange 1971, Rostron 1972, Heptner et al. 1989, Rebholz et al. 1991, 
Thouless and Al Basri 1991, Karami and Groves 1992). The delimitation of several species remains controversial, and a new species, G. bilkis, has been described as recently as 1975 (Groves 1988). The diploid chromosome number in the genus Gazella ranges from $2 \mathrm{n}=30$ to $2 \mathrm{n}=58$, but the number of chromosomal arms varies only from $2 n=56$ to $2 \mathrm{n}=58$ (Wurster and Benirschke 1968, Wurster 1972, Wahrman et al. 1973, Effron et al. 1976, Buckland and Evans 1978, Benirschke et al. 1984, Kumamoto and Bogart 1984, Furley et al. 1988, Arroyo Nombela et al. 1990, Granjon et al. 1991, Gallagher and Womack 1992, Vassart et al. 1993a, 1993b, 1995a, 1995b). Accordingly, translocations of the Robertsonian type are the prevalent mode of cytogenetic evolution in Gazella spp. These centric fusions can also be observed as polymorphism within populations: In 27 captive-bred Soemmerings gazelles, Benirschke et al. (1984) found twelve different karyotypes $(2 \mathrm{n}=34-39)$, caused by three Robertsonian translocations. Each of three investigated males had a different karyotype, and twelve of twenty analyzed females differed as well (Benirschke et al. 1984). The considerable cytogenetic diversity in some species of Gazella spp., as defined by skull morphology, horn shape and pigmentation, could indicate that the reproductive communities cannot be recognized from the outward apperance alone. However, chromosomal diversity in taxonomic species could also represent intra-population polymorphism. In a first step to a better understanding of gazelle systematics, the available database must be broadened by karyotyping many more population samples.

Gazelles are bred regularly in many zoological gardens (Bogsch 1983, Benirschke 1985, Olmedo et al. 1985, Ryder 1987, Alados et al. 1988), and are among those zoo-living mammals for which deleterious effects of inbreeding have been best documented. Frequently, a low reproductive performance (high perinatal or juvenile mortality) correlated positively with the genealogical relatedness of the parents (Ralls et al. 1980, Templeton and Read 1984, Templeton et al. 1987, Alados and Escos 1991). The existence of phenotypically cryptic chromosomal lineages complicates collection planning further, because the controversial taxonomy, and the chromosomal polymorphism of gazelles, imply the risk of genetic incompatibility when different cytotypes are crossed (Benirschke 1985, Ryder 1987, Kingswood and Kumamoto 1988).

The present study concerns the genetic variability of a zoo-living herd of the Persian goitred gazelle, Gazella subgutturosa subgutturosa (Güldenstaedt, 1780). The goitred gazelle is a phenotypically distinct member of its genus, and it is sometimes separated from other Gazella spp. as the monotypic subgenus Trachelocele (Rostron 1972, Heptner et al. 1989). Goitred gazelles were formerly very abundant throughout their extensive range in south-west and central Asia, and are still common in some regions (Zhirnov and Lushchekina 1992). However, free-ranging populations of $G$. s. subgutturosa have disappeared from several localities (Brooke 1873, Kumerloeve 1969, 1978, Išunin 1978, Lobacev et al. 1978, Heptner et al. 1989, Ogurlu 1992). The related and even more vulnerable sand gazelle, G. s. marica, was subject to a captive-breeding and research programme 
in Saudi Arabia and in North American zoos, which included cytogenetic and allozyme investigations (Kingswood and Kumamoto 1988, Granjon et al. 1991, Launay and Launay 1992, Rietkerk et al. 1992, Williamson et al. 1992, Habibi et al. 1993, Vassart et al. 1993b, Kingswood et al. 1994). In contrast, the population genetic variability of $G$. s. subgutturosa has not previously been investigated.

Karlsruhe Zoo (Karlsruhe, Germany) keeps one of the largest and most prolific captive breeding groups of $G$. subgutturosa subgutturosa. However, this herd exhibits an extremely high mortality of newborns and juveniles; in certain years, up to $50 \%$ or more of newborns die during their first days of life (C. Becker, pers. comm.). A studbook has never been kept for zoo-living Persian gazelles, and inbreeding coefficients could not be calculated from the unknown pedigree. Still, it is certain that only few specimens have been exchanged between zoos during the last decades. In light of the documented inbreeding depression in captive-bred gazelles (refs. above), it was considered likely that the poor reproductive performance of the herd at Karlsruhe Zoo was related to the population genetic background. We thus initiated a genetic analysis to check if karyotypically diverse lineages had been crossed at Karlsruhe Zoo, to recognize the degree of allozyme variability remaining in this herd after some generations of uncoordinated inbreeding, and to gain allelic markers for pedigree reconstruction.

\section{Material and methods}

Blood samples were collected from the jugular veins of 33 goitred gazelles. Four of the investigated specimens had been bred at Zürich Zoo, the other samples were provided by the breeding group from Karlsruhe Zoo. Details on the history of this herd are not available. This ignorance extends to the number and the origin of founder animals, and to their relative contribution to the gene pool. Goitred gazelles at Karlsruhe Zoo have been bred over a few decades in isolation, and inbreeding is assumed to be high. However, the gazelles have been tagged only recently, and the genealogy of the herd is entirely unknown.

The blood cell enzymes were assayed in horizontal agarose gels as described previously (Schreiber et al. 1997), and transferrin by PAGE as detailed by Schreiber and Matern (1989). The alleles of polymorphic loci are designated according to their relative electrophoretic mobilities, equating the most common variant with " 100 ". Chromosomes were prepared from lymphocyte cultures grown for 72 hours in chromosome medium B (Seromed, Berlin) at $37^{\circ} \mathrm{C}$. The metaphases were arrested by colchicine treatment for two to six hours. Subsequently, the preparations were fixed, and washed repeatedly, in methanol/acetic acid. The chromosomes were spread by dropping the cell nuclei on glass plates, and visualized by Giemsa staining. An average of 15 metaphases, air-dried on glass slides, were photographed and analysed per specimen (range: 8-25 metaphases).

\section{Results}

Allozymes, haemoglobins and plasma proteins representing 33 putative genetic loci were assayed in the blood samples from up to 33 zoo-living goitred gazelles. The zymograms of the following proteins represented one coding locus each: 
Carbonic anhydrase $(\mathrm{Ca})$, malate dehydrogenase $(\mathrm{Mdh})$, glyoxalase $(G l o)$, superoxide dismutase $(S o d)$, purine nucleoside phosphorylase $(N p)$, isocitrate dehydrogenase $(I c d)$, 6-phosphogluconate dehydrogenase $(P g d)$, mannose phosphate isomerase $(\mathrm{Mpi})$, phosphoglucomutase $(\mathrm{Pgm})$, adenosine deaminase (Ada), and catalase (Cat). Adenylate kinase $(A k-1, A k-2)$, lactate dehydrogenase $(L d h-1, L d h-2)$, glucose-phosphate isomerase (Gpi-1, Gpi-2) and acid phosphatase (Acp-1, Acp-2) displayed widely spaced activity zones, indicating the products of two coding loci each. Three loci with NADH diaphorase activity were expressed in blood cells. However, only two proteins (Dia-1, Dia-2) could be reliably scored in each individual. Four different loci with esterase activity (Es-1, Es-2, Es-3, Es-4) were visible when methyl-umbelliferyl acetate was used as the substrate. The haemoglobin of adult gazelles resolved into two clearly spaced bands, reminding of the red cell pigment of blackbuck (Antilope cervicapra), where this band duplication is known to reflect the duplication of $\alpha$-globin chains which are present in addition to the single $\beta$-globin (Shinde and Furtado 1981). We assume the same protein structure for the homologue of adult goitred gazelles, which therefore consists of three different protein chains. Calves displayed still another haemoglobin, presumably a persisting fetal globin. Thus, three haemoglobin loci were assayed in each adult gazelle, and an additional one in calves. Together with the serum proteins transferrin and albumin, 32 loci were scored in adult gazelles, and a 33rd locus in the calves only.

Four loci displayed biallelic polymorphism: Carbonic anhydrase (alleles $\mathrm{Ca}^{100}$ and $\left.\mathrm{Ca}^{184}\right)$, mannose-phosphate isomerase $\left(\mathrm{Mpi}^{100}\right.$ and $\left.\mathrm{Mpi}^{92}\right)$, and transferrin $\left(T f^{100}\right.$ and $\left.T f^{85}\right)$ were monomeric proteins, malate dehydrogenase $\left(M d h^{100}\right.$ and $\left.M d h^{110}\right)$ a dimeric enzyme. In addition to the 33 scored proteins, malic enzyme $(\mathrm{Me})$ displayed variable zymograms. However, this variation could not be resolved sufficiently for allelic interpretation, and it is omitted from this survey. Clearly, this locus deserves attention in future studies. Neglecting the questionable $M e$ variants, four out of 33 loci were polymorphic, ie the polymorphism was $P=0.121$. The Hardy-Weinberg-expectation of the heterozygosity amounted to $H_{e}=0.047$. Table 1 lists the genotype numbers of the four polymorphic loci, the allele

Table 1. Number of genotypes (100 - major allele, $x$ - rarer allele), allele frequencies ( $p_{100}$ - main allele, $\mathrm{p}_{\mathrm{x}}$ - rarer variant), observed $\left(H_{o}\right)$ and expected $\left(H_{e}\right)$ heterozygosities for four polymorphic proteins in captive-bred goitred gazelles. $n$-sample sizes.

\begin{tabular}{|c|c|c|c|c|c|c|c|}
\hline \multirow{2}{*}{ Alleles } & \multirow{2}{*}{$n$} & \multicolumn{3}{|c|}{ Genotypes } & \multicolumn{2}{|c|}{ Allele frequencies } & \multirow{2}{*}{$\begin{array}{c}\text { Heterozygosity } \\
H_{o} / H_{e}\end{array}$} \\
\hline & & $100 / 100$ & $100 / \mathrm{x}$ & $\mathrm{x} / \mathrm{x}$ & $\mathrm{p}_{100}$ & $\mathrm{px}$ & \\
\hline $\mathrm{Ca}^{100} / \mathrm{Ca}^{184}$ & 30 & 19 & 11 & 0 & 0.817 & 0.183 & $0.367 / 0.299$ \\
\hline$M d h^{100} / M d h^{110}$ & 33 & 14 & 12 & 7 & 0.606 & 0.394 & $0.364 / 0.478$ \\
\hline$M p i^{100} / M p i^{92}$ & 33 & 26 & 3 & 4 & 0.833 & 0.167 & $0.091 / 0.278$ \\
\hline$T f^{100 /} T f^{85}$ & 16 & 3 & 10 & 3 & 0.500 & 0.500 & $0.625 / 0.500$ \\
\hline
\end{tabular}


A

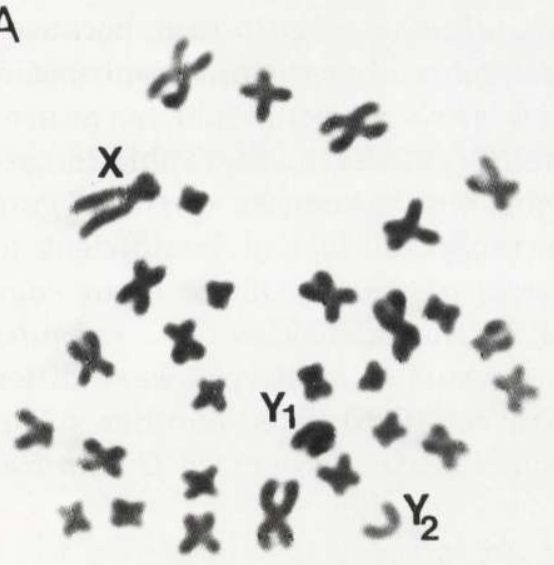

B

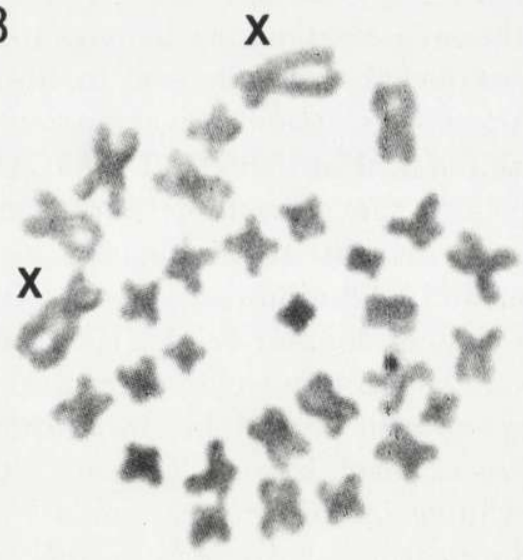

Fig. 1. Metaphase spreads of the G-stained chromosomes of the Persian gazelle (Gazella subgutturosa sugutturosa). A. Male, $2 \mathrm{n}=31$. B. Female, $2 \mathrm{n}=30$. $\mathrm{X}=\mathrm{X}$-chromome which originated via translocation to an autosome. $\mathrm{Y}_{1}, \mathrm{Y}_{2}=$ unpaired heterosomes of the male sex.

frequencies, the observed heterozygosities and their Hardy-Weinberg expectations. Four gazelles imported from Zürich Zoo exhibited the same alleles as did the animals from Karlsruhe Zoo. However, the imported individuals were fixed for the allele $M p i^{92}$ exclusively, although this variant was rare in the other breeding group.

Six male and seven female goitred gazelles were karyotyped. The complement of males comprised 31 chromosomes (Fig. 1A), including 14 pairs of meta-or submeta-centric, one large metacentric (ie the X-chromosome), and two unpaired acrocentric chromosomes $\left(\mathrm{Y}_{1}, \mathrm{Y}_{2}\right)$. Female karyotypes of 30 chromosomes also comprised 14 pairs of meta-submetacentrics, and two large metacentric X-chromosomes (Fig. 1B). Acrocentrics were absent from the karyotypes of female gazelles. The numerical difference between the sexes is due an X-autosomal translocation, leading to two fairly large X-chromosomes in females (Fig. 1B). In the male sex, the single $\mathrm{X}$-chromosome was complemented by two acrocentrics, $\mathrm{Y}_{1}$ and $\mathrm{Y}_{2}$ (Fig. 1A). Further numerical polymorphism of the chromosomes was not observed between individuals.

\section{Discussion}

The exact geograhic origins of the founder individuals of the herd at Karlsruhe Zoo are unknown (C. Becker, pers. comm.). Goitred gazelles inhabit a very large geographic range, from the trans-Caucasian countries to Tibet and the Godi desert 
(Blanford 1873, Brooke 1873, Heptner et al. 1989). However, there is no doubt that the investigated herd belongs to $G$. subgutturosa subgutturosa, because horns are confined to the male sex. In the second generally recognized subspecies, the sand gazelle ( $G$. subgutturosa marica) from the Arabian peninsula, horns are found in both sexes (Heptner et al. 1989). Despite the extensive geographic range of the subspecies, the phenotypic variation among regional stocks of $G$. subgutturosa subgutturosa has been reported as being only subtle and insufficient for the recognition of further subspecies (Heptner et al. 1989). Of the eight suggested forms which Heptner et al. (1989) lumped in the subspecies G. s. subgutturosa, only one population (reginae from Tsaidam) would suggest very weak differences of the external phenotype. In addition, Groves (1985) listed another subspecies, G. s. yarkandensis, from Xinjiang, and Groves (1988) recognized G. s. hillieriana from China and Mongolia.

\section{Cytotaxonomic homogeneity}

The karyotypes reported by Wurster (1972; three females) and by Effron et al. (1976; two males, one female) for an unspecified subspecies of $G$. subgutturosa may or may not refer to G. s. subgutturosa. As in the herd from Karlsruhe Zoo, males were found to have $2 \mathrm{n}=31$ and females $2 \mathrm{n}=30$ chromosomes (Wurster 1972, Effron et al. 1976). Granjon et al. (1991) cited a further report on chromosome numbers, describing $2 \mathrm{n}=30$ and $2 \mathrm{n}=31$ for goitred gazelles from China, where only G. s. subgutturosa is expected to occur (but see the classification by Groves 1988). The sand gazelle ( $G$. subgutturosa marica) displays variable autosome numbers. Kingswood and Kumamoto (1988) described karyotypes of $2 \mathrm{n}=31$ to 2 $\mathrm{n}=33$ for male and $2 \mathrm{n}=30$ to $2 \mathrm{n}=32$ for female sand gazelles from Jordan. They tentatively interpreted this diversity as the result of hybridization between G. s. marica and G. s. subgutturosa, because Jordan is located close to the contact zone of the distribution ranges of both subspecies. However, the same polymorphism was confirmed by Granjon et al. (1991) and Vassart et al. (1993) for many sand gazelles collected in Saudi Arabia clearly outside the subspecies contact zone. This finding contradicts the hybridization hypothesis and it appears that populations of the sand gazelle may contain chromosomal polymorphism. Kingswood et al. (1994) showed that heterozygotes for this Robertsonian polymorphism did not suffer from disturbed spermatocyte maturation.

The karyotypes of G. s. subgutturosa from Karlsruhe Zoo appeared homogeneous, except for the different chromosome numbers between the sexes mentioned. Sex-specific chromosome numbers are a widespread characteristic of Gazella spp. and of the closely related Antilope cervicapra (Wahrman et al. 1973, Effron et al. 1976, Vassart et al. 1995b), and therefore do not necessarily indicate the hybridization of cytotypes. In G. soemmeringi (Benirschke et al. 1984) or G. dama (Arroyo Nombela et al. 1990), X-autosome and Y-autosome translocations produce an even more complex sex-determining mechanism of $\mathrm{X}_{1} \mathrm{X}_{2} \mathrm{Y}_{1} \mathrm{Y}_{2}$ for males, and $\mathrm{X}_{1} \mathrm{X}_{1} \mathrm{X}_{2} \mathrm{X}_{2}$ 
for females. Tissue samples suitable for karyotyping from freshly deceased newborn $G$. s. subguturosa were not available. Therefore, karyotypic disorders could not be excluded directly as the cause of elevated perinatal mortality. However, a sizeable portion of the herd has been karyotyped, including several important breeders. Therefore, additional karyotypic diversity should probably have become obvious from this sample, if present in this breeding group and revealed by Giemsa staining. Thus, the herd of G. s. subgutturosa at Karlsruhe Zoo displays lower chromosomal variation than at least some populations of $G$. subgutturosa marica (refs above). This difference may reflect a genuine cytogenetic difference between two subspecies, or indicate the loss of a translocation polymorphism during the breeding history of the captive lineage.

\section{Allozyme variability}

The present data contribute another taxon to the growing database on the biochemical-genetic variability of gazelles (Table 2). At the same time, the published allozyme investigations of gazelles permit an evaluation of the present data (Table 2), although differences in the screening methods, and in the numbers and the identities of the investigated proteins complicate comparisons. Despite being captive-bred without a studbook, the goitred gazelles from Karlsruhe Zoo display allozyme variability which roughly resembles the values reported for other Gazella spp., including the conspecific sand gazelles from enclosures in Saudi Arabia (Table 2). Their heterozygosity surpasses the level encountered in zoo-living blackbuck, Antilope cervicapra, which has been derived by the same electrophoretic methods (Schreiber et al. 1997). Three proteins, Tf, Gpi and Np, out of 20 electrophoretic loci analyzed in 30 sand gazelles from King Khaled Wildlife Research Center near Riyadh (Saudi Arabia), were polymorphic (Granjon et al. 1991). Of these, $T f$ variation was confined to a single heterozygote in the subsample of 19 G. s. marica from the Mahazat as Said Reserve (Granjon et al. 1991). The $N p$ polymorphism was also restricted to the herd from Mahazat as Said Reserve, and the second allele at the Gpi locus also displayed a rather low frequency (Granjon et al. 1991). Both electrophoretic studies of $G$. subgutturosa proteins covered captive individuals with unknown pedigrees. Of the polymorphisms observed in the herd at Karlsruhe Zoo, Mdh and $M p i$ were monomorphic in the sand gazelle sample (Granjon et al. 1991), while $\mathrm{Ca}$ had not been investigated previously.

\section{Breeding management}

This study was initiated after the observation of a very high juvenile mortality in the herd at Karlsruhe Zoo: A high percentage of calves died during their first days of life, without obvious signs of disease or malformation. The present data provide no evidence that goitred gazelles belonging to phenotypically inconspicuous chromosomal races have been crossed. With appropriate management the herd still has some potential for developing a studbook population. The allozyme 
Table 2. Variability of protein electromorphs in gazelle species. $P$ - fraction of polymorphic loci. $H-$ percentage of heterozygous patterns (for springbok and blackbuck, the expected heterozygosity is provided, calculated on the basis of allele frequencies; the other studies indicate values of observed heterozygosity). n.s. - not specified. ${ }^{1}-$ isozyme loci, ${ }^{2}-$ isozymes, haemoglobins and plasma proteins.

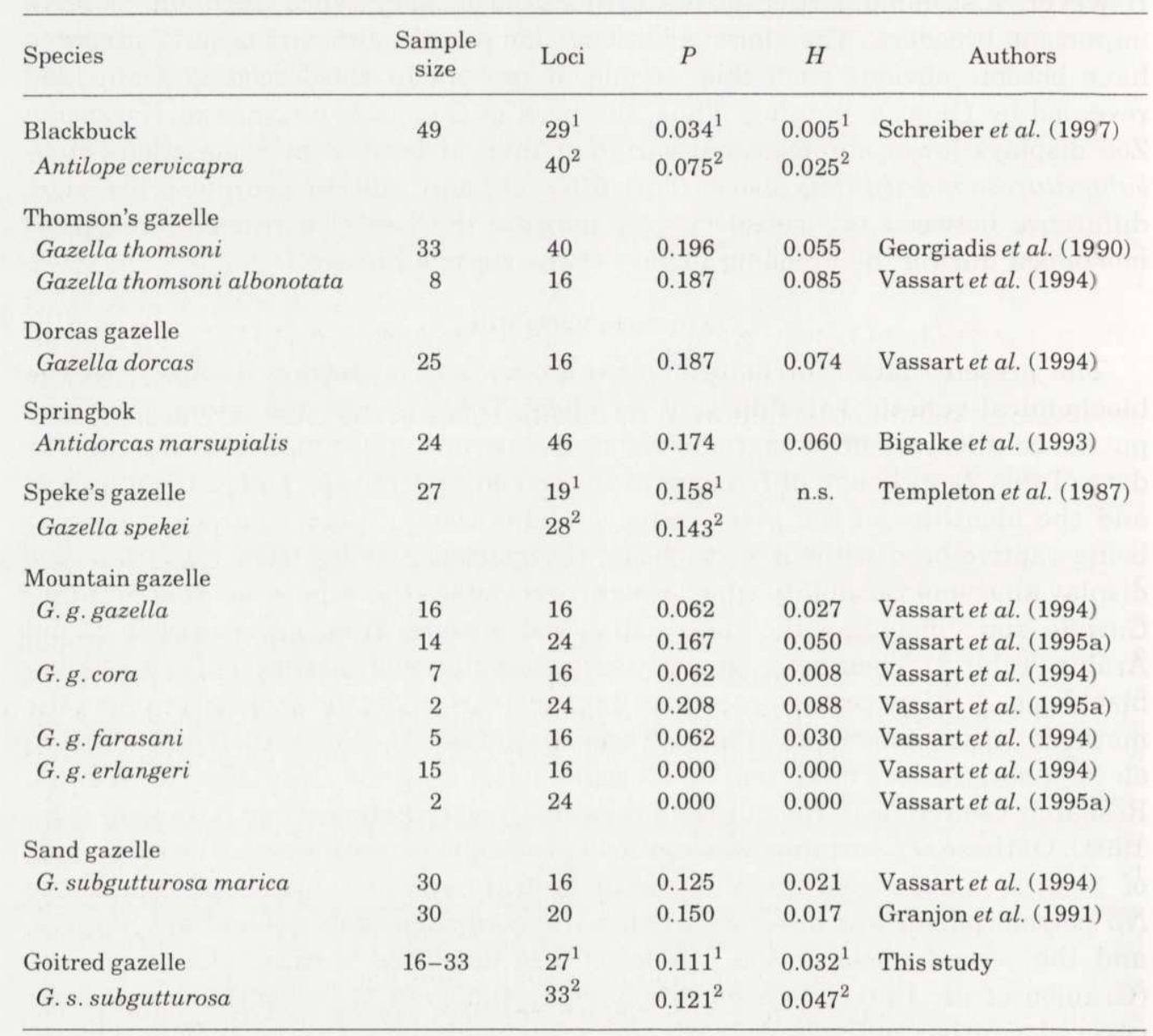

polymorphism does not appear conspicuously diminished either, when compared with previous studies of gazelle species (Table 2). However, free-ranging populations of the goitred gazelles could be more polymorphic than other gazelle species studied before, and the observed degree of genetic variability could merely reflect a remnant of a much higher original variation of the wild stocks. Moreover, lethal genes may have reached a high frequency in the captive herd despite the preservation of a notable genetic variability. Clearly, electrophoretic surveys alone are unable to identify, or to exclude, inbreeding depression as the cause of a poor reproductive performance. 
A marked infant mortality for unspecified reasons has also been reported for populations of free-ranging goitred gazelles, eg $40-50 \%$ by the first autumn (Sludskii, cited in Heptner et al. 1989). In the King Kahled Wildlife Research Centre, Saudi Arabia, where several hundred sand gazelles are kept in large enclosures, $25.6 \%$ of offspring died within one month post partum (177 recorded deaths from a total of 691 births), a percentage which varied from $15.3 \%$ in 1990 to $34.1 \%$ in 1991 (Rietkerk et al. 1992). Perinatal mortality accounted for $44.5 \%$ of the total mortality observed in this institution. Predation by foxes or birds was responsible for $39.1 \%$ of this juvenile mortality, and stillbirths added another $6.2 \%$. Habibi et al. (1993) did not metion stillbirths or juvenile mortality in his study of 90 reproducing female sand gazelles from the King Khaled Wildlife Research Centre. Ralls et al. (1980) reported a high perinatal (and juvenile) mortality of $29 \%$ in captive-bred dorcas gazelles $(G$. dorcas), with the statistically significant difference of $43 \%$ for inbred, but only $18 \%$ for non-inbred calves. Reproductive performance could not be improved by modifications of the enclosure design, diet, or by the provision of selenium or vitamin E. Prematurity, inanition and miscellaneous medical problems proved to be the main mortality factors (Ralls et al. 1980). Templeton and Read (1984) and Templeton et al. (1987) inferred inbreeding depression from stillbirths, abortions and juvenile mortality correlating with inbreeding coefficients in a herd of Speke's gazelle $(G$. spekei) from St. Louis Zoo, and estimated the number of five lethal equivalents for each of the founder specimens. The genetic variability (28 allozyme loci, restriction sites of mtDNA and ribosomal nuclear DNA) of these Speke's gazelles was inconspicuous as far as the percentage of polymorphic loci was concerned, but their heterozygosity has not been specified (Templeton et al. 1987). In a captive herd of Cuvier's gazelle (G. cuvieri), the inbreeding coefficients correlated with the survival of juveniles too (Alados and Escos 1991). Efforts to reduce inbreeding by increasing the exchange of individuals caused social aggression which resulted in mortality too (Alados et al. 1988). Social stress has been observed to impair the reproductive performance of Cuvier's gazelle mothers (Alados and Escos 1992).

Obviously, various factors can reduce the fertility of captive gazelles. The crucial test for the possible role of inbreeding depression would be provided by correlating the perinatal mortality of captive Persian gazelles with the inbreeding coefficients of their parents. Since the goitred gazelles at Karlsruhe Zoo were only recently tagged, there is no knowledge of the herds genealogy, and we are unable to correlate inbreeding coefficients with fitness parameters of the individuals. In this situation, the tentative modification of the keeping conditions should be considered, because factors other than inbreeding depression (eg social stress) may well explain the unsatisfactory breeding record. However, the present study does provide a basis for the subsequent monitoring of this herd. Pedigree controls, taking advantage of the allelic markers identified by this screening, and the continued tagging of all offspring are essential measures to reach this aim. 


\section{References}

Alados C. L., Escos J. and Vericad J. R. 1988. Captive populations of Northwest African Antilopinae and Caprinae at the Estacion Experimental de Zonas Aridas. [In: Conservation and biology of desert antelopes. A. Dixon and D. Jones, eds]. Christopher Helm, London: 199-211.

Alados C. L. and Escos J. M. 1991. Phenotypic and genetic characteristics affecting lifetime reproductive success in female Cuvier's, dama and dorcas gazelles. Journal of Zoology 223: 307-321.

Alados C. L. and Escos J. M. 1992. Determinants of social status and the effect of female rank on reproductive success in dama and Cuvier's gazelles. Ethology, Ecology and Evolution 4: 151-164.

Alados C. L. and Escos J. M. 1994. Variation in the sex ratio of a low dimorphic polygynous species with high levels of maternal reproductive effort: Cuvier's gazelle. Ethology, Ecology and Evolution 6: 301-311.

Arroyo Nombela J. J., Rodiguez Murcia C., Abaigar T. and Vericad J.R. 1990. GTG-banded karyotype of Gazella dama mhorr Bennett, 1833. Zeitschrift für Säugetierkunde 55: 194-201.

Benirschke K. 1985. The genetic management of exotic animals. Symposia of the Zoological Society London 54: 71-87.

Benirschke K., Kumamoto A. T., Olsen J. H., Williams M. M. and Oosterhuis J. 1984. On the chromosomes of Gazella soemmeringi Cretzschmar, 1826. Zeitschrift für Säugetierkunde 49: $368-373$.

Bigalke R. C. Hartl, G. B. Berry M. P. S. and van Hensbergen J. 1993. Population genetics of the springbok Antidorcas marsupialis - a preliminary study. Acta Theriologica 38, Suppl. 2: 103-111.

Blanford W. T. 1873. Note on the gazelles of India and Persia, with description of a new species. Proceedings of the Zoological Society, London 1873: 313-318.

Bogsch I. 1983. Zuchtergebnisse bei Dorkasgazellen, Gazella dorcas (L.), im Zoo Budapest. Zoologischer Garten N.F. 53: 309-312.

Brooke V. 1873. On the antelopes of the genus Gazella, and their distribution. Proceedings of the Zoological Society, London 1873: 535-554.

Buckland R. A. and Evans H. J. 1978. Cytogenetic aspects of phylogeny in the Bovidae, G-banding. Cytogenetics and Cell Genetics 32: 64-71.

Effron M., Bogart M. H., Kumamoto A. T. and Benirschke K. 1976. Chromosome studies in the mammalian subfamily Antilopinae. Genetica 46: 419-444.

Furley C. W., Tichy H. and Uerpmann H.-P. 1988. Systematics and chromosomes of the Indian gazelle, Gazella bennetti (Sykes, 1831). Zeitschrift für Säugetierkunde 53: 48-54.

Gallagher D. S. and Womack J. E. 1992. Chromosome conservation in the Bovidae. Journal of Heredity 83: 287-298.

Georgiadis N. J., Kat P. W., Oketch H. and Patton J. 1990. Allozyme divergence within the Bovidae. Evolution 44: 2135-2149.

Granjon L., Vassart M., Greth A. and Cribiu E.-P. 1991. Genetic study of sand gazelles Gazella subgutturosa marica) from Saudi Arabia. Zeitschrift für Säugetierkunde 56: 169-176.

Groves C. P. 1969. On the smaller gazelles of the genus Gazella de Blainville, 1816. Zeitschrift für Säugetierkunde 34: 38-60.

Groves C. P. 1983. Notes on the gazelles. IV. The Arabian gazelles collected by Hemprich and Ehrenberg. Zeitschrift für Säugetierkunde 48: 371-381.

Groves C. P. 1985. An introduction to the gazelles. Chinkara 1: 4-16.

Groves C. P. 1988. A catalogue of the genus Gazella. [In: Conservation and biology of desert antelopes. A. Dixon, D. Jones, eds]. Christopher Helm, London: 193-198.

Habibi K., Thouless C. R. and Lindsay N. 1993. Comparative behaviour of sand and mountain gazelles. Journal of Zoology 229: 41-53.

Heptner V. G., Nasimovich A. A. and Bannikov A. G. 1989. Mammals of the Soviet Union. Volume I, Ungulates. Brill, Leiden: 3-1147. 
Išunin G. I. 1978. Protection of Gazella subgutturosa Güld. in Uzbekistan. Second International Congress of Theriology, 20-27 June 1978, Brno: 301.

Karami M. and Groves C. P. 1992. A mammal species new for Iran: Gazella gazella Pallas, 1766 (Artiodactyla, Bovidae). [In: Proceedings of the International Symposium "Ongulés/Ungulates 91", Toulouse, September 2-6, 1991. F. Spitz, G. Janeau, G. Gonzalez, S. Aulagnier, eds]. Société Française pour l'Étude et la Protection des Mammifêres, Paris, Institut de Recherche sur les Grands Mammiferes. Paris, Toulouse: $361-364$.

Kingswood S. C. and Kumamoto A. T. 1988. Research and management of Arabian sand gazelles in the U.S.A. [In: Conservation and biology of desert antelopes. A. Dixon, D. Jones, eds]. Christopher Helm, London: 212-226.

Kingswood S. C., Kumamoto A. T., Sudman P. D., Fletcher K. C. and Greenbaum I. F. 1994. Meiosis in chromosomally heteromorphic goitred gazelle, Gazella subgutturosa. Chromosome Research 2: $37-46$.

Kumamoto A. T. and Bogart M. H. 1984. The chromosomes of Cuvier's gazelle. [In: One medicine. O. A. Ryder and M. L. Byrd, eds]. Berlin, Springer-Verlag: 101-108.

Kumerloeve H. 1969. Bemerkungen zum Gazellenvorkommen im südöstlichen Kleinasien. Zeitschrift für Säugetierkunde 34: 113-120.

Kumerloeve H. 1978. Verschwindet die Kropfgazelle, Gazella subgutturosa (Güldenstaedt, 1780), als Glied der türkischen Tierwelt? Säugetierkundliche Mitteilungen 26: 239-240.

Lange J. 1971. Ein Beitrag zur systematischen Stellung der Spiegelgazellen (Genus Gazella Blainville, 1816; Subgenus Nanger Lataste, 1885). Zeitschrift für Säugetierkunde 36: 1-18.

Launay F. and Launay C. 1992. Daily activity and social organization of the goitered gazelle (Gazella subgutturosa marica). [In: Proceedings of the International Symposium "Ongulés/Ungulates 91", Toulouse, September 2-6, 1991. F. Spitz, G. Janeau, G. Gonzalez and S. Aulagnier, eds]. Société Française pour l'Étude et la Protection des Mammiferes, Paris, Institut de Recherche sur les Grands Mammiferes. Paris, Toulouse: 373-377.

Lobacev V., Dmitrijev P. and Davaa N. 1978. Gazella subgutturosa and Equus hemionus in Southern Mongolia. Second International Congress of Theriology, 20-27th June 1978, Brno: 288.

Olmedo G., Escos J. and Gomendio M. 1985. Réproduction de Gazella cuvieri en captivité. Mammalia 49: 501-507.

Ogurlu I. 1992. Wild ungulates of Turkey. [In: Proceedings of the International Symposium "Ongulés/ /Ungulates 91", Toulouse, September 2-6, 1991. F. Spitz, G. Janeau, G. Gonzalez and S. Aulagnier, eds]. Société Française pour l'Étude et la Protection des Mammiferes, Paris, Institut de Recherche sur les Grands Mammiferes. Paris, Toulouse: 575-577.

Ralls K., Brugger K. and Glick A. 1980. Deleterious effects of inbreeding in a herd of captive dorcas gazelle. International Zoo Yearbook 20: 137-146.

Rebholz W. E. R., Williamson D. and Rietkerk F. 1991. Saudi gazelle is not a subspecies of dorcas gazelle. Zoo Biology 10: 485-489.

Rietkerk F. E., Lindsay N. and Tatwany H. 1992. Population dynamics of a captive herd of Arabian sand gazelles. [In: Proceedings of the International Symposium "Ongulés/Ungulates 91", Toulouse, September 2-6, 1991. F. Spitz, G. Janeau, G. Gonzalez and S. Aulagnier A., eds]. Société Française pour l'Étude et la Protection des Mammiferes, Paris, Institut de Recherche sur les Grands Mammiferes. Paris, Toulouse: 379-382.

Rostron J. 1972. A multivariate statistical study of skull measurements of five taxa of gazelles. Biological Journal of the Linnean Society 4: 1-14.

Ryder O. A. 1987. Conservation action for gazelles: an urgent need. Trends in Ecology and Evolution 2: $143-144$.

Schreiber A., Fakler P. and Østerballe, R. 1997. Low allozyme heterozygosity in blackbuck (Antilope cervicapra), a lekking gazelle. Zeitschrift für Säugetierkunde 62: 239-249.

Schreiber A. and Matern B. 1989. Genetic investigations and pedigree analysis in captive Barbary sheep (Ammotragus lervia Pallas 1777). Zoo Biology 8: 253-264 
Shinde R. and Furtado M. 1981. Probable gene duplication in $\alpha$-chain locus of the blackbuck Antilope cervicapra. Indian Journal of Experimental Biology 19: 1197-1198.

Templeton A. R. and Read B. 1984. Factors eliminating inbreeding depression in a captive herd of Speke's gazelle (Gazella spekei). Zoo Biology 3: 177-199.

Templeton A. R., Davis S. K. and Read B. 1987. Genetic variability in a captive herd of Speke's gazelle (Gazella spekei). Zoo Biology 6: 305-313.

Thouless C. R. and Al Basri K. 1991. Taxonomic status of the Farasan Island gazelle. Journal of Zoology 223: 151-159.

Vassart M. 1994. Évolution et diversité génétique chez les gazelles (Gazella); apports de lélectrophorse des protéines, de la cytogénétique et des microsatellites. Thesis, Université Paris-Sud., Paris: $1-258$.

Vassart M., Greth A., Durand V. and Cribiu E. P. 1993a. An unusual G. dama karyotype. Annals of Genetics 36: 117-120.

Vassart M., Greth A., Durand V. and Cribiu E. P. 1993b. Chromosomal polymorphism in sand gazelle, Gazella subgutturosa. Journal of Heredity 84: 478-481.

Vassart M., Granjon L., Greth A. and Catzeflis F. M. 1994. Genetic relationships of some Gazella species: an allozyme survey. Zeitschrift für Säugetierkunde 59: 236-245.

Vassart M., Granjon L. and Greth A. 1995a. Genetic study of Gazella gazella: Chromosomal and allozymic data. Comptes Rendues de l'Académie des Sciences Paris, Sciences de la Vie 318: 27-33.

Vassart M., Séguéla A. and Hayes H. 1995b. Chromosomal evolution in gazelles. Journal of Heredity 86: $216-227$.

Wahrman J., Richler C., Goiten R., Horowitz A. and Mendelssohn H. 1973. Multiple sex chromosome evolution, hybridization and differential X-chromosome inactivation in gazelles. Chromosomes Today 4: 434-435.

Williamson D. T., Tatwany H. and Rietkerk F. E. 1992. Temperature lability in the Arabian sand gazelle. [In: Proceedings of the International Symposium "Ongulés/Ungulates 91", Toulouse, September 2-6, 1991. F. Spitz, G. Janeau, G. Gonzalez and S. Aulagnier, eds]. Société Française pour l'Étude et la Protection des Mammiferes, Paris, Institut de Recherche sur les Grands Mammiferes. Paris, Toulouse: 349-352.

Wurster D. H. 1972. Sex chromosome translocations and karyotypes in Bovidae tribes. Cytogenetics 11: 197-207.

Wurster D. H. and Benirschke K. 1968. Chromosome studies in the superfamily Bovoidea. Chromosoma 25: $152-171$

Zhirnov L. V. and Lushchekina A. A. 1992. The ungulates of the Eurasian arid zone (problkems of conservation and rational use). [In: Proceedings of the International Symposium "Ongulés/ /Ungulates 91", Toulouse, September 2-6, 1991. F. Spitz, G. Janeau, G. Gonzalez and S. Aulagnier, eds]. Société Française pour l'Étude et la Protection des Mammiferes, Paris, Institut de Recherche sur les Grands Mammiferes. Paris, Toulouse: 339-342.

Received 1 September 1997, accepted 16 November 1998. 